\title{
Serum Level of Desert Hedgehog Protein in Autism Spectrum Disorder: Preliminary Results
}

\author{
Shahid Bashir ${ }^{a}$ b Dost Muhammad Halepoto ${ }^{b}$ Laila Al-Ayadhi ${ }^{b}$ \\ a Division of Cognitive Neurology, Berenson-Allen Center for Noninvasive Brain Stimulation, Department of \\ Neurology, Beth Israel Deaconess Medical Center, Harvard Medical School, Boston, Mass., USA; ${ }^{b}$ KSU-Autism \\ Research and Treatment Center, Department of Physiology, Faculty of Medicine, King Saud University, Riyadh, \\ Saudi Arabia
}

\section{Key Words}

Hedgehog protein · Desert hedgehog · Autism spectrum disorder

\begin{abstract}
Objective: To investigate the role of desert hedgehog (Dhh) in a neurodevelopmental disorder known as autism. Subjects and Methods: This study was conducted at the Autism Research and Treatment Center, King Khalid University Hospital, Riyadh, Kingdom of Saudi Arabia from October 2011 to May 2012. The serum levels of the Dhh protein in 57 patients recently diagnosed with autism and 37 age-matched healthy children were measured using ELISA. The Childhood Autism Rating Scale (CARS) was used for the assessment of autistic severity. Results: The mean serum level of Dhh in patients with autism $(1.38 \pm 0.50 \mathrm{ng} / \mathrm{ml})$ was significantly lower $(p=$ $0.0003)$ than that of normal controls $(1.73 \pm 0.37 \mathrm{ng} / \mathrm{ml})$. There was no significant relationship between the serum level of Dhh and the CARS score $(p=0.28)$, age $(p=0.51)$ or gender $(p=0.76)$. Conclusions: The Dhh serum level of patients with autism was lower than that of controls, probably indicating that the serum level of Dhh might be implicated in the physiology of autism. However, this finding should be treated with caution until further investigations are performed with larger populations.

(c) 2013 S. Karger AG, Basel
\end{abstract}

\section{KARGER}

E-Mail karger@karger.com www.karger.com/mpp
(C) 2013 S. Karger AG, Basel $1011-7571 / 14 / 0231-0014 \$ 39.50 / 0$

This is an Open Access article licensed under the terms of the Creative Commons Attribution-NonCommercial 3.0 Unported license (CC BY-NC) (www.karger.com/OA-license), applicable to the online version of the article only. Distribution permitted for non-commercial purposes only.

\section{Introduction}

Sixty years ago, Leo Kanner first labeled brain development disorder as autism spectrum disorder (ASD), and since then its cause and treatment have been poorly understood $[1,2]$. However, autism is no longer defined by etiology or pathology but by the presence of a pattern of behavioral characteristics that accompany a particular developmental course, with evidence of developmental delay within the first 3 years of life [1-4].

Hedgehog proteins are involved in many essential developmental processes in vertebrates and invertebrates [5]. The protein produced from the desert hedgehog (Dhh) gene is believed to be involved in male sexual development (spermatogenesis) and in the formation of the perineurium, the protective membrane around each bundle of fibers within a nerve [6]. This process involves the recruitment of neurons, glia (Schwann cells), blood vessels, fibroblasts, and extracellular matrix to build a structure that allows the ready and uninterrupted conduction of impulses along axons in an environment that is subject to ongoing movement and continuous mechanical stress.

We have recently reported that the serum levels of the Sonic hedgehog (Shh) protein and brain-derived neurotrophic factor (BDNF) might be linked to oxidative stress in ASD $[4,7]$. The Dhh and Shh proteins belong to the 
Hedgehog family. However, the role of activating Dhh signaling in these diseases is still elusive. The excess of neurotrophins and neuropeptides in sera of newborn infants has a predictive value in determining the children who will later have a disruption of intellectual and or social development. Biological markers have to be found that may allow earlier detection of autism. Thus the aim of the current study was to explore a possible role of the Dhh protein in children with autism.

\section{Subjects and Methods}

\section{Participants}

Fifty-seven children (53 boys and 4 girls) with ASD were recruited for this study with a mean age of $6 \pm 1.72$ years (range: $3-11$ years), and 37 (33 males and 4 females) age- and sex-matched healthy children (mean age: $7.04 \pm 1.74$ years; range: $3-11$ years) served as controls. The diagnosis of ASD was made by a child neuropsychiatrist (S.B.) and a pediatrician (D.M.) based on the criteria of ASD as defined in the DSM-IV [2] on the day of the screening test. The Childhood Autism Rating Scale (CARS) was completed as a further measurement of the severity of ASD [8]. The CARS rates the child on a scale from 1 to 4 in each of 15 areas (relating to people; emotional response; imitation; body use; object use; listening response; fear or nervousness; verbal communication; nonverbal communication; activity level; level and reliability of intellectual response; adaptation to change; visual response; taste, smell and touch response and general impressions). Written consent was obtained from the parents of each subject, according to the guidelines of the Ethics Committee of King Khalid Hospital, King Saud University, Riyadh, Saudi Arabia. All procedures that followed were in accordance with the Helsinki Declaration. This study was conducted at the Autism Research and Treatment Center, King Khalid University Hospital, Riyadh, Kingdom of Saudi Arabia from October 2011 to May 2012.

\section{Blood Samples}

After an overnight fast, a 3-ml blood sample was collected from each subject (autism and control) in plain test tubes. Blood samples were allowed to clot, and then centrifuged at 3,000 rpm to collect serum samples, which were stored frozen in a freezer at $-80^{\circ} \mathrm{C}$ until the time of analytical assays. A detailed description of the procedure has been described previously $[4,9]$. All samples were assayed in duplicate and in a double-blind manner. The assay reproducibility generally ranged from 5 to $10 \%$ error.

Dhh Assay

The serum level of Dhh was measured using a commercially available sandwich enzyme immunoassay (ELISA) kit from CUSABIO BIOTECH Co. Ltd. (Wuhan, China).

\section{Statistical Analysis}

The data are presented as means \pm standard deviation. Statistical differences were ascertained by using Student's $t$ test with significance set at a $p$ value of 0.05 or lower. The relationship between Dhh levels and the CARS among patients with autism was evaluated by computing Pearson's correlation coefficients.

Desert Hedgehog and Autism Spectrum Disorder

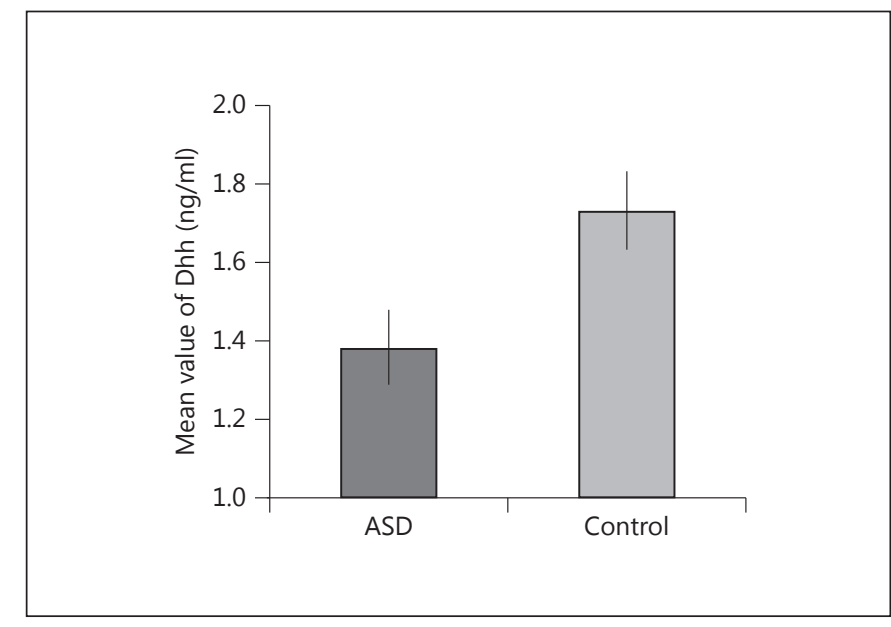

Fig. 1. Serum levels of the Dhh protein in control and autistic children. Highly statistically significant Dhh serum level in autism compared to control $(\mathrm{p}=0.003)$.

\section{Results}

The demographic data of the autistic and control subjects are given in table 1 . There were no significant differences in the male/female ratio or age between the two study groups. The serum $D h h$ levels of the patients (1.38 $\pm 0.50 \mathrm{ng} / \mathrm{ml}$ ) were significantly lower than those of normal control subjects $(1.73 \pm 0.37 \mathrm{ng} / \mathrm{ml} ; \mathrm{p}=0.0003$; fig. 1 ; table 1). The scores on the CARS range from 15 to 60 , whereas individuals with scores lower than 30 are categorized as nonautistic. A CARS score between 30 and 36.5 $(\mathrm{n}=31)$ indicates mild to moderate autism and scores ranging from 37 to 60 indicate severe autism $(n=26)$. The mean serum level of patients with mild to moderate autism $(\mathrm{n}=31$ and CARS score $<36.5)$ was $1.36 \pm 0.48 \mathrm{mg} / \mathrm{l}$ while that of those with severe autism ( $\mathrm{n}=26$ and CARS score $>36.5$ ) was $1.39 \pm 0.6 \mathrm{ng} / \mathrm{ml}$. The difference was not statistically significant $(\mathrm{p}=0.26)$.

Further, the serum Dhh levels of autistic subjects had no significant correlation with their age $(\mathrm{p}=0.51)$.

\section{Discussion}

The current study is the first to demonstrate a significant decrease in Dhh serum levels in subjects with autism as compared to normally developing controls. Although caution should be exercised in the interpretation of our data, they suggest a potential role for Dhh factors in this neurodevelopmental disorder. 
Table 1. Serum levels of Dhh in autistic children and their relation to the severity of autism

\begin{tabular}{lccccc}
\hline & Age, years & Gender & Dhh, ng/ml & p value & $\begin{array}{c}\text { CARS } \\
\text { score }\end{array}$ \\
\hline Patients with autism $(\mathrm{n}=57)$ & $6 \pm 1.72$ & 53 male, 4 female & $1.38 \pm 0.50$ & \\
Patients with mild to moderate autism $(\mathrm{n}=36)$ & $6 \pm 1.38$ & 33 male, 3 female & $1.36 \pm 0.49$ & $<0.004^{\mathrm{a}}$ \\
Patients with severe autism $(\mathrm{n}=21)$ & $6 \pm 2.06$ & 20 male, 1 female & $1.39 \pm 0.61$ & $<0.05^{\mathrm{b}},<0.64^{\mathrm{c}}$ & $<36.5$ \\
Healthy children $(\mathrm{n}=37)$ & $7.04 \pm 1.74$ & 33 male, 4 female & $1.73 \pm 0.37$ & $<0.0003^{\mathrm{d}}$ \\
\hline
\end{tabular}

Figures for age and $D h h$ are given as means \pm SD.

${ }^{a}$ Comparing control subjects with mild to moderate autistic children. ${ }^{b}$ Comparing control subjects with severe autistic children. ${ }^{\mathrm{c}}$ Comparing mild to moderate with severe autistic children. ${ }^{\mathrm{d}}$ Comparing control subjects with autistic children.

Thus, while there is clearly a variety of Dhh in individuals with autism, these two facts imply two things. ary marker of the disease rather than directly pathogenic. Second, individual children with a similar clinical phenotype have very different immune responses to the protein we studied. The results demonstrated no significant correlation between the severity of autism and serum Dhh levels in autistic subjects.

The serum levels of the Shh protein and BDNF might be linked to oxidative stress in ASD as has recently been reported $[4,7]$. BDNF is a small protein found throughout the CNS and peripheral blood. BDNF is the most widely distributed neurotrophin in the CNS. Within the nervous system, the Shh protein is associated with the development and patterning of the CNS $[10,11]$. We have shown a reduction in BDNF in ASD children in a previous report [4]. BDNF belongs to the neurotrophin family that may affect neuronal survival and differentiation. Dhh is a morphogen important for the nerve development $[6,12]$. During the inflammatory episode, molecules affecting the nerve functions, such as ion channels, and with long-term effects involving inflammatory tissue damage are secreted [13]. Since Dhh signaling is an important factor in building the barriers that protect nerves against mechanical assault and inflammation-related damage, the significantly lower Dhh serum levels found in autistic subjects as compared to controls could be part of the pathophysiology in autism, and Dhh may exert a neuroprotective effect.

The chief caveats of our report are the small sample size and its cross-sectional design. We thus observed associations, not prediction or causation. These caveats notwithstanding, we have demonstrated an alteration of the Dhh levels in patients with autism characterized by a clear imbalance of important Dhh factors. First, the presence of these Dhh proteins may be a second-

\section{Conclusion}

The Dhh serum levels of patients with autism were lower than those of controls, probably indicating that the serum level of Dhh might be implicated in the physiology of autism. However, these data should be treated with caution until further investigations are performed, with larger samples, to determine whether the lower serum levels of Dhh are a mere consequence of autism or have a pathogenic role in the disease.

\section{Acknowledgements}

Work on this study was supported by grants from the King Abdulaziz City for Science and Technology, the National Plane of Science and Technology Health Research program, and the Deanship of Scientific Research grant (RGP-VPP-216) from King Saud University, Saudi Arabia.
References

Med Princ Pract 2014;23:14-17 DOI: $10.1159 / 000354295$
1 Kanner L: Autistic disturbances of affective contact. Nerv Child 1943;2:217-250.

2 American Psychiatric Association: Diagnostic and Statistical Manual of Mental Disorders, Text Revision. Washington, American Psychiatric Association, 2000.

- 3 Fombonne E: Epidemiology of pervasive developmental disorders. Pediatr Res 2009;65: 591-598.

4 Al-Ayadhi LY: Relationship between Sonic hedgehog protein, brain-derived neurotrophic factor and oxidative stress in autism spectrum disorders. Neurochem Res 2012;37: 394-400.

5 Pathi S, Pagan-Westphal S: Comparative biological responses to human Sonic, Indian, and Desert hedgehog. Mech Dev 2007;106:107117.
16 
6 Hashimoto K, Koizumi H, Nakazato M, et al: Role of brain-derived neurotrophic factor in eating disorders: recent findings and its pathophysiological implications. Prog Neuropsychopharmacol Biol Psychiatry 2005;20: 499-504.

-7 Canto P, Vilchis F, Söderlund D, Reyes E, Méndez JP: A heterozygous mutation in the desert hedgehog gene in patients with mixed gonadal dysgenesis. Mol Hum Reprod 2005; 11:833-836.
-8 Schopler E, Reichler RJ, DeVellis RF, Daly K: Toward objective classification of childhood autism: Childhood Autism Rating Scale (CARS). J Autism Dev Disord 1980;10:91103.

-9 Mostafa GA, Al-Ayadhi LY: Increased serum levels of anti-ganglioside M1 auto-antibodies in autistic children: relation to the disease severity. J Neuroinflammation 2011;8:39.

10 Banerjee SB, Rajendran R: Recruitment of the sonic hedgehog signalling cascade in electroconvulsive seizure-mediated regulation of adult rat hippocampal neurogenesis. Eur J Neurosci 2005;22:1570-1580.
1 Hurtado-Lorenzo A, Millan E, GonzalezNicolini V, Suwelack D, Castro MG, Lowenstein PR: Differentiation and transcription factor gene therapy in experimental Parkinson's disease: sonic hedgehog and Gli-1, but not Nurr-1, protect nigrostriatal cell bodies from 6 OHDA induced neurodegeneration. Mol Ther 2004;10:507-524.

12 Hooper JE, Scott MP: Communicating with hedgehogs. Nat Rev Mol Cell Biol 2005;306317.

13 Riobo NA, Manning DR: Pathways of signal transduction employed by vertebrate Hedgehogs. Biochem J 2007;369-379. 